\title{
THE CONCEPT OF DEGRESSIVE AND PROGRESSIVE PROPORTIONALITY AND ITS NORMATIVE AND DESCRIPTIVE APPLICATIONS
}

\begin{abstract}
The article discusses the concept of progressive and degressive proportionality of the distribution of parliamentary seats. In the first part are presented axiological sources of the principles of proportionality and progressive and degressive proportionality and the history of degressively proportional apportionments of seats in the European Parliament. The main part of the article is devoted to the formulation of proposals for strict formal definition of degressive and progressive proportionality, and a description of the method of apportionment of seats in the European Parliament based on the strict definition of degressive proportionality and maintaining maximum compatibility with former apportionments adopted in multilateral negotiations. The last part of the article consists of a discussion of the possibilities of adopting the concept of progressive proportionality in the analysis of the functioning of parliamentary electoral systems.
\end{abstract}

Keywords: proportionality, degressive proportionality, electoral systems, proportional elections, fair decisions.

"Proportionality" is one of the criteria for fair distribution of goods: if there are many contenders for a divisible good, and their entitlement to it is different, the proportionality principle says that the shares allocated to each of them should be proportional to the measure of entitlement that has been accepted. In particular situations, implementing this principle may pose difficulties of different kinds, e.g. resulting from the imperfect divisibility of a good or its heterogeneity. However, the difficulty may also lay in determining what measure of entitlement should be accepted. The proportionality principle can be used whenever differences in the level of entitlement are merely quantitative, and the good to be distributed is homogeneous. For example, it could not always be applied in such cases as division of an estate in bankruptcy among creditors (differences between creditors do not solely concern the size of the claim: the law treats differently e.g. tax offices 
and employees of the bankrupt, and the latter are treated differently from all other creditors), or division of the estate among heirs (an inheritance may consist of heterogeneous goods that are not directly comparable to one another; in this case, however, the proportionality principle can be used following the conversion of heterogeneous goods into homogeneous ones, by selling the items included in the inheritance and dividing the money proportionately). However, not in every case, even if the proportionality principle can be applied, is it considered as the appropriate measure for justice. An example could be the diverse methods applied when dividing an estate in bankruptcy among creditors, which do not necessarily follow the method of ranking creditors by priority as applied under Polish law, but e.g. require to apply equal, as opposed to proportional, division in instances where it is impossible to satisfy all claims (Young, 1994, p. 64nn).

One of the areas where the proportionality principle is used is election law. The proportional distribution of seats can be used with regard to two categories of those "entitled". Firstly, concerning the distribution of seats among electoral districts (or, more generally, territories) and secondly, the distribution of seats among parties (electoral lists). Determining the "measure of entitlement" is not a problem when seats are allocated to parties (the measure is expressed by the number of votes cast by voters). For allocating seats to districts, the population figure may be applied as the "measure of entitlement", but it could also be the number of those entitled to vote or even the number of votes cast in a district, so determining an appropriate measure is a matter of reaching political consensus. ${ }^{1}$ A major problem, regardless of whether allocating seats between parties or districts, derives from the fact that, although seats are a homogeneous good (so it is important for a party/district to learn "how many" seats it will get rather than "what seats"), still this good cannot be divided entirely (a party or district has to obtain whole numbers of seats - therefore, if 10 seats are to be distributed and a district "is entitled" to $1 / 3$ of them, it cannot receive exactly $31 / 3$ seats). In other words, as a rule strictly proportional distribution is impossible; what can be reached is distribution "nearest to proportionality"; which of the possible forms of distributions is "nearest to proportionality" will depend on what criterion is adopted to assess the proportionality of distribution.

The problem of distributing seats among territories is even greater wherever territories predate the election system itself. This concerns especially situations where seats are distributed between federal entities, as was the case of allocating seats in the House of Representatives to individual states in the USA, or the case of allocating seats in the European 
Parliament to individual member countries of the EU. These are situations in which, on the one hand, appropriate representation of local interests is of great importance, but on the other hand, participants in the distribution are entities with very diverse characteristics, especially with regard to size: Wyoming, the smallest state in the USA in terms of population, has a population over 70 times smaller than the largest one, California; and the smallest member country of the EU, Malta, is over 197 times smaller than Germany. Where districts are formed more or less arbitrarily, merely for election system purposes (like e.g. in Polish proportional elections to the lower chamber of the parliament, Sejm), the least that can be done is to ensure that the districts do not differ too much in size, and possible distortions of the distribution of seats among districts would be less important to voters than having appropriate representation of individual groups of interest or ideological positions, represented by parties. As a result, although the issue of dividing seats among territories is older than that of dividing seats among parties, it has generally aroused less interest either from public opinion or politicians, except for the examples mentioned above.

For over 200 years, researchers and politicians have developed in the USA and Europe a number of methods for proportional distribution of seats - in the USA for the purpose of allocating seats to states before elections, while in Europe to parties after elections. Among these methods, the most frequently used are: the largest remainders method, attributed to A. Hamilton in the USA and to Th. Hare and H. Niemeyer in Europe; the Jefferson-d'Hondt method and the Webster-Sainte-Laguë method. Neither the methods used to distribute seats nor their properties are the subject of this paper - those interested are invited to read other publications, such as (Young, 1994), (Balinski \& Young, 2001), (Haman, 2002), (Haman, 2003). The Webster-Sainte-Laguë method will be treated here as the "foundation" for proportional distribution of seats; arguments for this choice can be found in Balinski and Young's analysis (Balinski \& Young, 2001, p. 86), and in other researchers' work, especially that of V. RamirezGonzalez (Ramírez-González, 2010). This issue, however, plays only a technical part in further analysis in this paper ("degressively proportional" distribution could also be reached by an analogous modification of any other method used).

The fact that the issues of distributing seats among districts and among parties have, to a great extent, been analysed in parallel is not only due to historic reasons. These two problems may be treated as identical only as much as reaching proportionality is considered to be the only criterion. In 
many cases, however, it is not, and additional criteria, partly competing with proportionality (and so requiring compromises to be reached) for distribution of seats among districts are different from those of distribution among parties.

Why is it expected that distribution of seats must be proportional, anyway? It seems that there are two, more prior principles behind it, which will be discussed further:

- Equality criterion:

it is directly referred to by the principle "one man, one vote" defined in the context of elections. In some cases, such as a federal country or an international institution (e.g. the European Parliament), "equality" may be related not only to people (voters) but also to federation entities or member countries.

- Right to representation: nobody should be deprived of representation in parliament. Again, this principle may be related to voters (each significant interest group, and each minority, should have appropriate representation in parliament), as well as "collective entities" (each territory should have its representatives in parliament).

Both these principles are essential for distribution of seats among districts as well as for distribution of seats among parties, but the way it is applied may be different in these two contexts. Furthermore, in the case of distribution of seats among parties, there is yet another criterion: the effectiveness of an election process, whose ultimate goal is to confer power to the parliamentary majority.

\section{Equality vs. proportionality}

In the context of elections, the equality principle is frequently defined as "one man, one vote." This not only means that each voter has the right to throw one sheet of paper into a ballot box, but also that each vote should have the same chance to determine the result of an election. From this rule, it is easy to derive the principle of equal distribution of seats among districts: if a district has twice as many voters, it should delegate twice as many members to parliament. Such an approach guarantees there is equal voter representation in parliament.

The situation becomes complicated, however, if we take into consideration not only the subjectivity of individual voters but also the subjectivity of whole communities. While this issue is of no significance where the divi- 
sion into districts is mainly technical and arbitrary (which is very much the case of parliamentary elections in Poland), yet it is crucial in federal states, and even more so in international institutions. Allocation of seats in the US Congress to individual states of the USA was the subject of an agreement between the thirteen (then) independent states, which despite being radically different in terms of population figures, were still in fact equal. This problem is even more evident with regard to allocating seats in the decision-making bodies of the European Union, where equality of citizens is one criterion, but the other is the equality of the member states. These two are in obvious conflict: adopting Malta's equality with Germany would mean granting a single Maltese citizen almost two hundred times greater influence on the Union's decisions than a single German one. Conversely, adopting the rule of equality between a single German and Maltese as the only method would mean that Malta's voice might virtually be ignored in collective decisions.

It is impossible to simultaneously apply the principle of equality between people - leading to the proportionality rule - and that of equality between collective entities (provinces, states, countries): a compromise between these two rules must involve adopting an intermediate solution. The 1787 American constitutional compromise assumed proportional allocation of seats in the House of Representatives to the states, which is equal in the Senate (two seats per state), while in the United States Electoral College, which elects the President, the allocation is intermediate: the number of seats for each state equals the sum of the numbers of seats in the House of Representatives and in the Senate.

The situation in the European Parliament is different in that neither European treaties nor later agreements have ever introduced any strict rule that would determine distribution of seats among EU member countries - the distribution was agreed upon in the course of multilateral negotiations. From the very beginning, however, i.e. from the establishment in 1952 of the Common Assembly of the European Coal and Steel Community, a principle was applied which was later named the "degressive proportionality principle": each country was assigned a number of seats in between the numbers resulting from the principles of proportionality to population and equality between individual countries - members of the Union. Despite attempts made since the 1990s to define the "degressive proportionality" principle more precisely, or even to develop an explicit algorithm for distribution of seats, up until now seats in the EP have been distributed through arrangements, for which legal rules only provide a general framework. 


\section{The right to representation}

The right to be represented plays an essential part in shaping seat distribution systems - both distribution among parties after elections and distribution among territories before elections. For each of these cases, however, both its interpretation and influence on the solutions adopted differ significantly.

When seats are distributed among territories, the right to representation is absolute and superior to the proportionality principle: no territory may be deprived of representation, even if it appeared from the proportional distribution principles used that it should obtain no seats. Hence, Article I of the US Constitution orders that each state must have at least one seat in the House of Representatives. Since the 1970s, arrangements among the EU member states concerning seat distribution principles have stipulated that the minimum representation of a country in the European Parliament (EP) may not be lower than 5 or 6 seats. Note that a delegation consisting of e.g. 2 deputies would not be sufficient for representatives of a given country to be able to participate in the work of all essential EP commissions; neither would delegates from such a country be able to participate in all major parliamentary factions.

The situation is different when seats are distributed among parties. On the one hand, the very idea of proportional elections is mainly based on the assumption that all political powers, representatives of different interest groups or ideological positions, should be represented in the Parliament: in this sense, proportional representation is opposed to majority elections, in which "the winner takes all." On the other hand, to reach this goal, it is not necessary for distribution to be precisely proportional: it is more important that different groups have some representation rather than strict maintenance of the proportions between individual minority groups. Moreover, representation is not the only ultimate goal of an election; the point is also to select a winner. Among countries that use proportional representation, only a few, such as Switzerland with its extremely consensual system of government, adopt as a rule that all major powers participate in cabinet. Striving for effective selection of a winning parliament majority may justify using such solutions in the election system - also in proportional systems - that give advantage to larger parties and limit the parliament's fragmentation. These solutions include applying formulas which are more advantageous to larger parties (like the d'Hondt method), the use of electoral thresholds as well as distributing seats by districts rather than on the scale of the country as a whole, which raises the "nat- 
ural thresholds," often no less dangerous for small parties than statutory thresholds.

On the other hand, the "right to representation" principle with regard to distribution of seats among parties, as opposed to distribution among districts is relative: while in the latter case the system has to guarantee a representation from each territory, proportional election systems merely facilitate obtaining seats to representatives of (different) minorities, and no system can guarantee each party which manages to win some votes that they will obtain a seat; on the contrary, it will frequently be a hindrance to parties with low voter support. In other words, every voter has an a priori right to equal treatment, but if he supports a party that will not exceed the electoral threshold (whether statutory or natural) and hence will obtain no seats, his right to be represented will not be infringed.

\section{Progressive and degressive proportionality}

When seats are distributed among territories, the final criteria hierarchy is as follows: firstly, to ensure representation to all territories, and only then to ensure equality (which, for a federation, may require a balance between the principles of citizen equality and the equality of federation entities). When seats are distributed among parties, the proportionality principle (which secures the right to representation and equal treatment for political minorities) has to compete against a desire for the political effectiveness of an election system. Depending on what weight is attached to each of these criteria, the legislator may adopt different election systems - from the classic plurality ones, such as the British FPTP, to strictly proportional, such as the systems used in Holland or Israel, with intermediate solutions, such as the election system employed in Poland, which is proportional but uses both statutory thresholds and not very large electoral districts and, as a result, gives a considerable advantage to larger parties.

Consequently, methods of seat distribution among parties and among territories used in practice tend to depart from proportionality in opposite directions. When seats are distributed among territories - especially among federation entities, such as states, lands or countries forming an international organisation - we may expect degressive proportionality, i.e. a distribution in which a larger country is entitled to a greater number of seats than a smaller one, however each seat delegated to a larger country represents more citizens than a seat delegated to a smaller country. The systems of distributing seats among parties tend to favour larger parties: party A, which gains twice as 
much support from voters as party B, may expect more than twice as many seats. By analogy to degressive proportionality, such distribution should be called a progressively proportional distribution.

When analysing the degressiveness or progressiveness of proportional seat distribution, two approaches may be adopted: a normative and a descriptive approach. The former approach poses the question: in what way should seats be distributed for the distribution to be degressively/progressively proportional with a determined power of degression/progression? In the latter case, the question will concern the power of degression/progression of individual distributions.

In both cases, it is indispensable to answer the two following questions:

- How precisely can proportional distribution and degressively/progressively proportional distribution be defined?

- How can the power of proportionality progressivity or degressivity be measured?

These issues will be dealt with in further sections of this article. Since historically the issue of "degressively proportional distribution" is mainly connected with the history of allocating seats to national delegations in the European Parliament, I will present the definition of "degressive proportionality" and the resulting way of measuring the power of proportionality degression/progression against the background of discussions on the rules of seat distribution in the EP. This concept can be naturally generalized so that it includes both "degressive" and "progressive" proportionality. The latter may find interesting descriptive applications, first of all as a description of election systems that would enhance and specify previous methods of describing the "disproportionality" of seat distribution in parliaments.

\section{Degressively proportional distribution of seats in the EP}

The notion of "degressive proportionality" is usually connected with the principle behind the allocation of seats to national delegations in the European Parliament and its predecessor, the Common Assembly of the European Coal and Steel Community. According to a practice dating back to 1952, the number of delegates from the member states of the ECSC/EEC/EU to the European Parliament was determined in a way which ensured that there were more delegates from countries with larger populations, and that proportions of the number of delegates between large and small countries were smaller than the respective proportions of their populations. For example, in 1952 Luxembourg, with a population about 
250 times smaller than that of West Germany, had a delegation consisting of 4 deputies, while West Germany had 18 deputies - a number merely 4.5 times larger.

In subsequent terms of the European Parliament (this name was officially introduced in 1962) the sizes of delegations were modified, primarily when new member states were accepted to the Community, for whom it was necessary to determine the number of delegates. This often became an opportunity to resize the delegations of previous members. The numbers of delegates were determined through political negotiations, which meant that although they were related to the concept of "degressive proportionality," this concept did not have to be precisely defined and, in particular, was not an element of any legal norm.

The first attempt to replace agreements reached through political discussions with a strictly defined formula, which would refer to a specific definition of "degressive proportionality," was not made until 1992, when the European Parliament proposed, in a resolution from June $10^{\text {th }}$, that the new distribution of seats (change was forced by the fact of accepting Austria, Finland and Sweden to the Union along with the reunification of Germany) be based on a formula that would first allocate 6 seats to each country, and then one seat for each 500 thousand residents up to 25 million, one seat per each million residents between 25 million and 60 million, and one seat for each 2 million residents above 60 million. However, this rule did not find traction in practice, and the distribution of seats before the 1994 election again resulted from political agreements.

The next distribution of seats was agreed on at the 2000 Nice conference, and was applied in the 2004 election. This distribution took into account ten new countries (including Poland); what is more, seats were also provided for Bulgaria and Romania, which were to join the Union three years later. Coincidently, this was the first case when the number of delegates from "old" EU states (except for the smallest Union member, Luxembourg, and the largest Germany) was reduced when seats were redistributed. Until then, there had been an unwritten rule that demanded the protection of what was seen as "acquired laws" - each time when the Parliament's composition was corrected, care was taken that no country lost any seats once allocated. Consequently, the total number of members in the European Parliament increased from 78 to 626 between 1952-99, which is more than an eightfold increase, though the number of the member states in that period increased by 2.14, and the population grew less than twice. The Nice distribution method was applied only in one election, in 2004. It is in that year that the Intergovernmental Conference adopted a rule (and included 
it in the EU Constitutional Treaty and, following its failure, in the Treaty of Lisbon) according to which seats must be distributed in compliance with an (undefined) principle of "degressive proportionality," the size of national delegations must be between 6 and 96 deputies, and the total number of Parliament members must not exceed 750. In the Nice distribution, the minimum was 5 seats (for Malta), the maximum was 99 seats for Germany, and the total number of Parliament members was 785. These small divergences made it necessary to deal with the issue of allocation of seats once again.

Decisions about distribution of seats were to be taken outside of Parliament, but the European Parliament, as the main interested party, led discussions, this time not only on the distribution itself, but also on the principle behind it. An impulse for driving the discussion also came from the proposal of a distribution formula put forward in 2006 by V. Ramirez-Gonzalez (Ramírez-González, Palomares, \& Márquez, 2006; Ramírez-González, 2010), known as the "parabolic method" and promoted informally by Spain. The "parabolic method" deserves attention for two reasons. First, it was the first method based on a solid mathematical foundation that "got through" to politicians and policy makers, and although it ultimately failed to be adopted, it did contribute to developing interest in a formal approach to the issue of "degressive proportionality." Second, it provides a good, elegant example of how the problem of seat distribution can be solved by using an axiomatic method, in which the axioms include criteria worked out through political negotiations (in this case, the terms of distribution as stated in the Treaty of Lisbon). This does not mean, however, that this method was a good solution to the problem; in particular, it still used a very general interpretation of the notion of "degressive proportionality." (I present the parabolic method and its review in more detail in another article (Haman, 2007)). Although the parabolic method has been noticed by politicians, it finally failed to be applied, and distribution of seats was again agreed on through political negotiations.

In 2007, two deputies, Alain Lamassoure and Adrian Severin, were entrusted by the European Parliament with providing possible solutions to the problem of degressively proportional distribution of seats. On August $31^{\text {st }}$, 2007 they presented a report with a draft resolution later adopted by the European Parliament. On the one hand, they stated in the report that "the ideal alternative would be to agree on an undisputed mathematical formula of 'degressive proportionality' that would ensure a solution not only for the present revision but for future enlargements or modifications due to demographic changes ( $(10)$, , only to add moments later that "in fact there is not an abstract, impartial, good-for-all cases mathematical solution for a prob- 
lem that is essentially political (§11)." (As I will try to demonstrate later, this pessimism is unjustified to a great extent). The Lamassoure-Severin report also contains the first formal definition of "degressive proportionality" included in an official document: "the bigger the population of a Member State, the higher must be the number of inhabitants that each MEP represents; the smaller the population of a Member State is, the lower must be the number of inhabitants that each MEP of that Member State represents (§14)" (Lamassoure \& Severin, 2007). This definition is consistent with natural intuition about "degressive proportionality," but it is by far insufficient: we might say that by no means does it go beyond such intuition; what is more, it is in fact inaccurate, as it is easy to provide an example in which simultaneous fulfilment of both conditions is simply impossible. ${ }^{2}$

Ultimately, distribution of seats before the 2009 election was not based on an "unbiased mathematical formula." In January 2011, the EP Committee on Constitutional Affairs "commissioned a Symposium of Mathematicians to 'identify a mathematical formula for the distribution of seats which will be durable, transparent and impartial to politics"' (Grimmett, 2011, p. 4), with the participation of V. Ramirez-Gonzalez, as well as W. Słomczyński, K. Życzkowski, and others. What resulted from the symposium was a proposal named "the Cambridge compromise," even simpler than the EP's proposal of 1992. In summary, it assumes that a fixed number of seats would be allocated to each country, increased by a number of seats proportional to its population. Its application - after selecting optimal (i.e. leading to distributions closest to those previously agreed on) parameter values (which were determined by the symposium participants as 5 seats "for anyone" and one per each started 818,000 citizens) (Grimmet, 2011, p. 23) - would cause considerable changes in seat distribution. No wonder then that, although the results of the mathematicians' work gained recognition in the European Parliament and formed the basis for the Committee on Constitutional Affair's proposals, they were ultimately not applied during the distribution of seats before the 2014 election. The European Commission's decision of June $28^{\text {th }}, 2013$ introduced a distribution method only slightly divergent from that used in 2009. However, Article 4 of the Commission's decision repeats the promise that "This Decision shall be revised sufficiently far in advance of the beginning of the 2019-24 parliamentary term on the basis of an initiative of the European Parliament presented before the end of 2016 with the aim of establishing a system which in future will make it possible, before each fresh election to the European Parliament, to allocate the seats between Member States in an objective, fair, durable and transparent way, translating the principle of degressive proportionality 
as laid down in Article 1, taking account of any change in their number and demographic trends in their population, as duly ascertained thus respecting the overall balance of the institutional system as laid down in the Treaties."

\section{Degressive and progressive proportionality - an attempt to provide an exact definition}

The criticism of using "mathematical formulas" to distribute seats directly formulated in the above mentioned report by Lamassoure-Severin - refers to the claim that the problem of distribution of seats is primarily a "political" one. However, I am going to demonstrate that a strictly mathematical approach to the problem of distribution may also refer to the "political" parameter - so it does not have to disregard the tradition and existing customs surrounding the application of a political compromise.

In order to define the notion of degressive and progressive proportionality, we must first answer the question: "What is the proportionality of distribution about?".

Let us introduce the following symbols:

\begin{tabular}{|l|l|}
\hline$N=\{1,2, \ldots, k\}$ & Set of allocation participants (states, political parties) \\
\hline$p_{i}$ & $\begin{array}{l}\text { Measure of entitlement of } i \text { participant in the distribution } \\
\text { (e.g. population of } i \text { state, number of votes or percentage } \\
\text { of votes cast in favour of } i \text { party). }\end{array}$ \\
\hline$p_{0}=\sum_{i \in N} p_{i}$ & $\begin{array}{l}\text { The sum of measures of entitlements of all distribution participants } \\
\text { (e.g. total population of all EU member states) }\end{array}$ \\
\hline$u_{i}$ & $\begin{array}{l}\text { The size of share in a shared right, to which } i \text { participant } \\
\text { in the distribution is entitled (number of seats due). }\end{array}$ \\
\hline$a_{i}$ & $\begin{array}{l}\text { Number of units of a shared right allocated to } i \text { distribution } \\
\text { participant after taking into consideration the fact that it must } \\
\text { be an integer. }\end{array}$ \\
\hline $\begin{array}{l}u_{0}=a_{0}=\sum_{i \in N} u_{i} \\
=\sum_{i \in N} a_{i}\end{array}$ & $\begin{array}{l}\text { The total quantity of a right that is subject to allocation } \\
\text { (number of seats to be allocated) }\end{array}$ \\
\hline
\end{tabular}

We assume $p_{i}>0, u_{i} \geq 0, a_{i} \geq 0$ for all $i$.

Allocation of a distributable right between the entitled parties is strictly proportional to $p$ measure of entitlement, if for each couple of entitled $i$ and $j$

$$
\frac{u_{i}}{p_{i}}=\frac{u_{j}}{p_{j}}
$$


In the case of distributing seats between states in proportion to their population, it would mean that the proportion between the number of seats held by a given state and the population of that state is the same for all states.

This formula can be converted into the following form:

$$
\frac{u_{i}}{u_{j}}=\frac{p_{i}}{p_{j}} .
$$

according to which we demand that for each couple of states, the proportion of the number of allocated seats is equal to the proportion of the size of their entitlement.

Such proportions between the level of entitlement and the size of shares due are maintained between all the allocation participants if the share due to each of the participant equals

$$
u_{i}=a_{0} \frac{p_{i}}{\sum_{j \in N} p_{j}}=a_{0} \frac{p_{i}}{p_{0}} .
$$

There still remains the issue of transition from $u_{i}$ "due shares" that do not need to be expressed in integers, to $a_{i}$ allocated number of seats which must be integers. It is the method of solving the problem that forms the difference between individual methods of proportional distribution of seats ${ }^{3}$. As I have mentioned earlier, for the purposes of this article I shall assume that this problem has already been solved and that the "best possible" proportional distribution is a distribution made using the WebsterSainte-Laguë method. We will deal with that problem later; in this section, we focus on the due number of seats, even if such a number is not an integer.

So, we have established what a proportional distribution is about: for example, if the population of $i$ state is twice as large as the population of $j$ state, $i$ state is entitled to twice as many seats as $j$ state. So, what is degressively proportional distribution all about? It consists in that $i$ state shall have more seats than $j$ state, but less than twice as many. And exactly - how many more? It depends - if the distribution is to be strongly degressive, a larger state will be entitled only to a slightly larger share in seats than a smaller state; and if the degression is to be weak - the share of the bigger state is almost twice as large as the share of a smaller state. The power of degression is one of the parameters of a degressively proportional distribution that can be determined while designing the system. 
However, the allocation of seats in the EP between EU Member States has been made not on the basis of a "mathematical rule," but through negotiations. So, we can assume with even more certainty that the power of degression of such an allocation meets the expectations of Member States. So, let us try to determine it empirically.

In 2013, i.e. in the year of determining the size of delegations before the most recent EP elections, Hungary, with a population of 9,909 thousand, had 21 seats and Romania, with a population of 20,020 thousand, held 32 seats. This leads to the following proportions:

$$
\begin{aligned}
& \frac{p_{R}}{p_{W}}=\frac{20020}{9909}=2.02 \\
& \frac{a_{R}}{a_{W}}=\frac{32}{21}=1.52 .
\end{aligned}
$$

Because we do not have any other data concerning the size of shares due to Hungary and Romania (before rounding them to integers), we must assume that:

$$
\frac{u_{R}}{u_{W}}=1.52 .
$$

Therefore, assuming that the distribution of seats between Hungary and Romania agreed during negotiations reflects the "proper" power of degression quite well, we may assume that a state which is twice as big as the other one should be entitled to 1.52 times more seats. If this is the case, it should be assumed that a state which is four times larger should have 2.25 times more seats - in general, a state $k$ times bigger should acquire $1.5^{\log _{2} k}$ times more seats. As a consequence, using the properties of logarithms and exponential function, it is easy to find such a transformation of $p_{i}$ and $p_{j}$ values, the application of which will bring the proportions of two due $u$ shares to the proportions of transformed $p$ measures of entitlement:

$$
\begin{aligned}
\frac{u_{i}}{u_{j}} & =1.52^{\log _{2} \frac{p_{i}}{p_{j}}}=1.52^{\log _{2} 1.5 \log _{1.52} \frac{p_{i}}{p_{j}}}=\left(1.52^{\log _{1.52} \frac{p_{i}}{p_{j}}}\right)^{\log _{2} 1.52} \\
& =\left(\frac{p_{i}}{p_{j}}\right)^{\log _{2} 1.52}=\frac{p_{i}^{\log _{2} 1.52}}{p_{j}^{\log _{2} 1.52}}=\frac{p_{i}^{0.60}}{p_{j}^{0.60}}
\end{aligned}
$$

In other words, in order (a) for the proportions of due shares to depend only on proportions of the size of states and (b) for a country twice as large to be entitled to 1.5 times more seats, the distribution of seats 
should be in proportion to the number of residents raised to the power of 0.60 . The value 0.60 itself is a parameter describing the degressive power of distribution.

So, let us introduce a generalised definition of degressively and progressively proportional distribution.

Distribution is proportional, degressively proportional, or proportional when the proportion between $u_{i}$ and $u_{j}$ shares due to any two $i$ and $j$ distribution participants can be determined solely on the basis of data on the proportion between the size of their entitlement, $p_{i}$ and $p_{j}$, whereas

$$
\frac{u_{i}}{u_{j}}=\frac{p_{i}^{r}}{p_{j}^{r}}
$$

and the share size of $i$ participant equals to

$$
u_{i}=a_{0} \frac{p_{i}^{r}}{\sum_{j \in N} p_{j}^{r}}
$$

for a given degression/progression coefficient $r>0$. If the coefficient $0<r<1$, then the distribution is degressively proportional; if $1<r$, then the distribution is progressively proportional, if $r=1$, then the distribution is proportional.

An equivalent definition can be formulated by referring to the notion of adjustment function: Distribution is degressively proportional if for each $i \in N$, the size of $u_{i}$ share due to $i$ participant is proportional to $p_{i}$ measure of the size of his entitlement transformed by $f(p)=p^{r}$ adjustment function, where $0<r<1$; and if $r>1$, the distribution is progressively proportional. Using the concept of adjustment function, it is also possible to define a broader class of distribution methods. In particular, adjustment functions that are increasing and concave can be used to develop different methods of "degressively proportional distribution" as it is understood as the rule that a larger state has a larger share, but with a larger number of citizens per one seat than a smaller state. The "parabolic method" of V. Ramirez-Gonzalez was based on the fact that for properly chosen values of coefficients (especially for $a<0$ ) and a limited domain, the quadratic $f(p)=a p^{2}+b p+c$ function meets this requirement (Ramírez-González, 2010); however, it does not have such a precise interpretation as the method based on $f(p)=p^{r}$ function, which also is increasing and concave. 


\section{Determining the value of a degression coefficient on the basis of empirical data}

In the example mentioned above, we determined the value of the degression index $r=0.60$ for the distribution of seats in the European Parliament using one pair of countries: Romania and Hungary.

Of course, this procedure only makes sense when presenting the general meaning of this coefficient: in order to find $r$ value which best reflects the power of degression of the distribution of seats in the European Parliament, the data on the population and size of delegations for all states should be taken into consideration, at least for the states whose delegation exceeds 6 seats - as the size of the delegations of the smallest countries results not from the application of the rule of regressive proportionality, but rather from referring to the "right of representation." Therefore, such $r$ value should be found, for which the "degressively proportional" due shares will be suited best to the agreed and effective distribution of seats between all EU Member States, excluding those states who have been granted a minimum number of seats, i.e. Estonia, Cyprus, Luxembourg, and Malta.

The method of determining of how well the degressively proportional distribution is suited to actual distribution remains open for discussion. For practical reasons (availability of the tool within popular computer applications), I suggest using feasible (e.g. with SPSS) curve-fitting regression using the least square method ${ }^{4}$ with the following model:

$$
\hat{Y}=a X^{r}
$$

where $Y$ is the number of seats in the European Parliament, $X$ is the population of a state, $a$ and $r$ are regression parameters, where $r$ is the sought degression power coefficient and $a$ is the proportionality coefficient (for $r=1$, it is the average number of residents per 1 seat, for $r \neq 1$, this coefficient does not have a specific interpretation).

For data from $2014^{5}$, this method leads to the determination of $r=0.725$ value, where the square of Pearson's correlation coefficient between the number of seats "due" in accordance with the degressive proportionality principle using the so determined degression coefficient and the actual number of seats is over 0.99 .

Table 1 contains data on population, the number of EP seats and number of seats due in accordance with the degressive proportionality principle with $r$ coefficient of 0.725 , as well as the number of seats allocated by rounding the number of due seats using the Webster-Sainte-Laguë method 
The Concept of Degressive and Progressive Proportionality...

Table 1

\begin{tabular}{|c|c|c|c|c|}
\hline State & Population & $\begin{array}{c}\text { Number of } \\
\text { seats based } \\
\text { on the } 2013 \\
\text { decision of } \\
\text { the Council } \\
\text { of the EU }\end{array}$ & $\begin{array}{c}\text { Number of } \\
\text { seats due } \\
u_{i}\end{array}$ & $\begin{array}{c}\text { Number of } \\
\text { seats } \\
\text { rounded } \\
\text { using the } \\
\text { Webster- } \\
\text { Sainte-- } \\
\text { Laguë } \\
\text { method }\end{array}$ \\
\hline Germany & $80,523,746$ & 96 & 89.83 & 90 \\
\hline France & $65,633,194$ & 74 & 77.45 & 77 \\
\hline United Kingdom & $63,896,071$ & 73 & 75.95 & 76 \\
\hline Italy & $59,685,227$ & 73 & 72.29 & 72 \\
\hline Spain & $46,704,308$ & 54 & 60.51 & 60 \\
\hline \begin{tabular}{|l|} 
Poland \\
\end{tabular} & $38,533,299$ & 51 & 52.63 & 53 \\
\hline Romania & $20,020,074$ & 32 & 32.74 & 33 \\
\hline Netherlands & $16,779,575$ & 26 & 28.80 & 29 \\
\hline Belgium & $11,161,642$ & 21 & 21.43 & 21 \\
\hline Greece & $11,062,508$ & 21 & 21.29 & 21 \\
\hline Czech Republic & $10,516,125$ & 21 & 20.53 & 21 \\
\hline \begin{tabular}{|l|} 
Portugal \\
\end{tabular} & $10,487,289$ & 21 & 20.49 & 20 \\
\hline Hungary & $9,908,798$ & 21 & 19.66 & 20 \\
\hline Sweden & $9,555,893$ & 20 & 19.15 & 19 \\
\hline Austria & $8,451,860$ & 18 & 17.52 & 18 \\
\hline Bulgaria & $7,284,552$ & 17 & 15.72 & 16 \\
\hline Denmark & $5,602,628$ & 13 & 13.00 & 13 \\
\hline Finland & $5,426,674$ & 13 & 12.71 & 13 \\
\hline \begin{tabular}{|l} 
Slovakia \\
\end{tabular} & $5,410,836$ & 13 & 12.68 & 13 \\
\hline Ireland & $4,591,087$ & 11 & 11.25 & 11 \\
\hline Croatia & $4,262,140$ & 11 & 10.66 & 11 \\
\hline Lithuania & $2,971,905$ & 11 & 8.21 & 8 \\
\hline Slovenia & $2,058,821$ & 8 & 6.29 & 6 \\
\hline Latvia & $2,023,825$ & 8 & 6.22 & 6 \\
\hline \begin{tabular}{|l|} 
TOTAL NUMBER OF COUNTRIES \\
GIVEN MORE THAN 6 SEATS \\
\end{tabular} & $502,552,077$ & 727 & 727 & 727 \\
\hline Estonia & $1,324,814$ & 6 & & 6 \\
\hline Cyprus & 865,878 & 6 & & 6 \\
\hline \begin{tabular}{|l} 
Luxembourg \\
\end{tabular} & 537,039 & 6 & & 6 \\
\hline Malta & 421,364 & 6 & & 6 \\
\hline EU MEMBER STATES IN TOTAL & $505,701,172$ & 751 & & 751 \\
\hline
\end{tabular}

Population in 2013 according to Eurostat data. 
(see next section). It is worth mentioning that some of the discrepancies result from traditional, EP-specific quotas - such as the equal size of the representation of Italy and the United Kingdom or Belgium and Portugal; in this respect - no "unbiased mathematical method" is able to meet the politicians' expectations. Besides, it seems that by adjusting the value of $r$ parameter, determining the power of degression, on the basis of data on actual distribution of seats achieved through negotiations, it is possible to propose a method of distribution based on both unbiased mathematical criterion and a sense of righteousness, expressed in the process of negotiations between states.

\section{Determination of degressively proportional share using the Webster-Sainte-Laguë method}

So far, we have established how to determine the size of $u_{i}$ share $d u e$ to a given distribution participant. Let us also discuss how to get from $u_{i}$ that does not need to be an integer, to $a_{i}$, i.e. the number of allocated seats which must be an integer. We are going to achieve this by applying the Webster-Sainte-Laguë method to the distribution of seats, but instead of referring to the population of a given state (i.e. $p_{i}$ ), which is the case of proportional distribution, we shall refer to the population raised to the power of $r$ (i.e. $p_{i}^{r}$ ).

The Webster-Sainte-Laguë method can be described in two, seemingly different ways - as a method referring to the quota ${ }^{6}$ and rounding principle or as a method referring to the priority function. The second approach is used in the most popular algorithms, also the ones employed in voting systems ${ }^{7}$. In addition, algorithms referring to the priority function are of a sequential nature, which makes it easier to modify the method so that it meets additional requirements, e.g. concerning the maximum or minimum number of seats granted.

Let $a_{i}^{k}$ be the number of seats granted to $i$ state until the moment of making the decision to whom the next $k$-th seat should be allocated. The Webster-Sainte-Lague priority of $i$ state at the moment of allocating $k$-th seat shall be the following number:

$$
t_{i}^{k}=\frac{u_{i}}{a_{i}^{k}+0.5} .
$$

A distribution compliant with the Webster-Sainte-Laguë method is achieved by allocating subsequent seats to states (parties), who have the 
highest priority value at the moment of allocating a given seat. As the distribution depends on relative rather than absolute size of priorities, the above formula for $t_{i}^{k}$ can be modified by multiplying all values of $t_{i}^{k}$ by the same, positive constant. So, in the case of proportional distribution, we can use $p_{i}$ in the place of $u_{i}$ (for example, the state's population or number of votes cast in favour of a given party) and in the case of degressively or progressively proportional distribution, we use the $p_{i}^{r}$ value, which leads to the following alternative formula:

$$
t_{i}^{k}=\frac{p_{i}^{r}}{a_{i}^{k}+0.5} .
$$

It can be proven ${ }^{8}$ that the application of the above procedure would be identical to the following procedure: we determine $u_{i}$ numbers of seats due and then we multiply them by a common constant, chosen so that the modified values rounded to the nearest integer, after summing them up, give the value equal to the expected number of seats. After rounding $u_{i}$ values presented in Table 1 to the nearest integer, they will total 728 , whereas the number of seats to be distributed is 727 . However, if we multiply $u_{i}$ values by any number from $(0.99885 ; 0.99977)$ interval, after rounding the product to integer values, we will get the expected number of 727 seats and the distribution will be compliant with the Webster-Sainte-Laguë method.

The original Webster-Sainte-Laguë method does not guarantee that all distribution participants will get a seat. This is natural in the case of distribution of seats between parties, and in the case of distribution of seats between territories, additional requirements concerning the minimum number of allocated seats are added. The algorithm of sequential WebsterSainte-Laguë distribution can be easily modified so that it meets the above mentioned requirements, as well as possible requirements concerning the maximum number of allocated seats. In the case of the EP, such values are laid out in the Treaty on European Union, art. 14 clause 2 as 6 and 96 seats, respectively.

To sum up, degressively or progressively proportional distribution of $k$ seats between $n$ states (parties), adopting $a_{\min }$ and $a_{\max }$, as boundary conditions for the minimum and maximum number of seats granted to each distribution participant, using the Webster-Sainte-Laguë method, can be implemented with the following algorithm:

1. Each distribution participant is granted $a_{\min }$ seats.

2. The remaining $a_{0}-n \cdot a_{\min }$ seats are distributed in sequence, whereas each $k$-th seat is allocated to the participant, for whom the value of the priority function 


$$
t_{i}^{k}=\frac{p_{i}^{r}}{a_{i}^{k}+0.5},
$$

where it is the highest at a given moment. The participants, for whom $a_{i}^{k}=a_{\max }$ are omitted.

Of course, we assume that the boundary conditions are non-contradictory, so $a_{0} \geq n \cdot a_{\min }$ and $a_{0} \leq n \cdot a_{\max }$. If the distribution is to be proportional, then $r=1$; for a degressively proportional distribution $0<r<1$, for a progressively proportional distribution, $r>1$. If the rules of the distribution do not require that each member is granted any seats, we assume that $a_{\min }=0$; if the rules do not limit the maximum number of seats that a given participant can get (more precisely, that this number is limited only by the total number of seats to be distributed), then we assume that $a_{\max }=a_{0}$.

The application of the above rule for the distribution of seats between EP Member States, assuming that boundary values equal $0=751 a_{\min }=6$, $a_{\max }=96$, which results from the agreements between EU Member States contained in the Treaty on European Union, and the degression coefficient $r=0.725$, best reflecting the level of degression characterising the distribution of seats adopted in 2013, leads to the distribution of seats presented in the last column of Table 1 .

\section{Progressive and degressive proportionality: descriptive applications}

In the previous sections, I focused on the normative issue - i.e. on how to distribute seats to achieve a certain degression level and, in particular to maintain the degression level corresponding to the existing distributions while avoiding distortion of proportional distribution in a manner which is not only about the desire to introduce degression. In this section, I am going to suggest some possibilities for a descriptive application of the concept of degressive and progressive proportionality as a tool for describing the voting systems of individual states.

In most countries - also those using "proportional" voting systems - the distribution of seats between parties has indeed a progressively proportional nature. This may result from such factors as the application of formulas favouring large parties (such as the d'Hondt formula), especially in combination with small electoral districts, or the use of statutory thresholds, excluding smaller parties who are not able to get the minimum percentage of votes; lastly, in some systems, used to ensure a stable parliamentary majority, a party with the largest number of votes is granted an additional 
bonus to facilitate or guarantee an absolute majority in the House for that party. In states using plurality voting systems - the classic FPTP used in the UK or the "two-rounds" plurality system (used in France), the distribution of seats is even more favourable towards large parties. The variety and complexity of voting systems make it difficult to directly compare the voting systems in individual countries.

In voting analyses, the measures of disproportion of the distribution of seats are used (including the most popular Gallagher's index (Gallagher, 1991)). However, "disproportion" can either be the effect of some "randomness" in the operation of voting principles (meaning that the distribution of seats does not need to depend solely on the percentage of votes won by parties) or be an intentional rule adopted in the voting system - if its purpose is to increase the stability of the government.

Similarly, as in the case of determining the "degression power" for the distribution of seats in the EP, for each distribution of seats between parties it is possible to determine "progression power" as the value of $r$ coefficient resulting in a progressively proportional distribution which is suited best to the actual distribution of seats. For example, in elections to the Polish parliament in the years 1991-2015, progression coefficients were from 1.12 in 2001 up to 1.77 in 1993 (for the elections in $2015-1.44$ ) ${ }^{9}$; however, for individual EU Member States, progression coefficients for the most recent parliamentary elections ranged from 1.01 for Denmark and 1.02 for the Netherlands up to 1.80 for the UK and 1.84 for Hungary. ${ }^{10}$

Of course, in order to formulate any further conclusions concerning the characteristics of Polish and European voting systems would require a much more thorough analysis, taking into consideration both a suitably broad empirical data set, as well as detailed information on the principles of individual voting systems. However, the use of the suggested measure of progression of seat distribution could make such analyses much more detailed and refined.

\section{Summary}

Although the principle of "degressive proportionality" concerning the distribution of seats between national delegations in the EP has been in operation since 1950s, and attempts to define it clearly have been made at least since 1990, it has never been defined in a way which goes beyond the general formula laid out in the Lammasoure-Severin report, which states that "the bigger the population of a (...) the higher must be the number of 
inhabitants that each MEP represents; the smaller the population (...) the lower must be the number of inhabitants that each MEP of that Member State represents." However, it is possible to provide a strict definition of degressive proportionality and determine a single parameter describing its power - and such a proposal has been formulated in this article.

The degression coefficient can be determined by referring to empirical data, through matching the "degressively proportional distribution" (in its strict sense defined in this article) with historical distributions - assuming that the parameter of the problem of "degressive proportionality" is of a purely political nature (thus requiring an agreement by way of negotiations or, as in this case, reconstruction on the basis of historical negotiation results). This parameter (degression power) can be determined both in a strictly "mathematical" way, as well as in a way taking into consideration its "political nature."

By using such a method, we may achieve a distribution which is very close to the distribution adopted through long negotiations and at the same time having good theoretical (i.e. objective, not political) grounds. The analyses presented in this article also show that despite the expansion of the EU and growing number of EP members, the power of degression of the distribution has been more or less the same since the 1970s. Therefore, it seems that contrary to politicians' opinions, it is possible to develop a "mathematical formula of 'degressive proportionality' that would ensure a solution not only for the present revision but for future enlargements or modifications due to demographic changes" (which was postulated by the Lamassoure-Severin report, however, with no hope for implementation), being a "mathematical solution for a problem that is essentially political" (which Lamassoure and Severin believed was impossible).

The progressive/degressive nature of distribution of seats can also be analysed with reference to the results of parliamentary elections, both "proportional" elections - i.e. carried out using methods commonly called "proportional", but also "plurality" methods - if it is possible to determine the percentage of votes won by political parties in the whole country (i.e. when political affiliations of candidates are clearly defined). By using a similar method - finding a value of the "progression/degression coefficient" best suited to empirical results - we may create characteristics of the distribution of seats conveying other data than methods used previously. For example, "Gallagher's index," commonly used in voting analyses, only points to the size of "disproportion" of a given distribution. The application of the proposed "progression coefficient" enables us to tell the difference between "disproportion" as a set of non-intentional, random distortions of distribu- 
tion, and "progression" as the intended effect of the structure of the voting system, aimed to ensure not only universal representation, but facilitate stability of the government as well.

The exact concept of degressive and progressive proportionality can have normative applications - it enables us to design a system of seat distribution that meets specific requirements, both those of a political and historical nature, as well as those resulting from the theory of fair distribution of rights. The same concept can also be used for descriptive purposes: it allows us to quantify an important characteristic feature of actual distribution of seats in parliamentary elections, which is the tendency of voting systems to favour large parties - as the progression index.

\section{N O T E S}

1 Taking Polish political practice into account, at least after 1989, the issue of choosing an appropriate measure of district magnitudes was never the subject of a major political dispute. However, this may constitute an essential political issue, as is shown in the complex structure of Article I, section 2 of the US Constitution, according to which the size of representation from individual states in the House of Representatives was to be established proportionally, i.e. "according to their respective Numbers, which shall be determined by adding to the whole Number of free Persons, including those bound to Service for a Term of Years, and excluding Indians not taxed, three fifths of all other Persons."

2 Let us assume that there are 11 seats to be distributed between two countries with a population of 2,000 thousand and 1,999 thousand, respectively: if 6 of them are allocated to the larger country, its "representation norm" (333,333.3 citizens per seat) will be smaller than that of the smaller country (399,999.8 citizens per seat), which is inconsistent with the principle of degressiveness of distribution. If the larger country obtains 5 seats only, the smaller one will have more seats than the larger one. Obviously, there would be no problem, if e.g. the "number of seats theoretically due" was used instead of introducing a norm referring to the "number of seats allocated." As can be seen, it is a problem of lacking language precision, which is indispensable in this type of issues.

${ }^{3}$ It is worth mentioning that if all $u_{i}$ values were integers (so that no "rounding" was necessary), the methods of Hare-Niemayer, Jefferson-d'Hondt and Webster-SainteLaguë would give each country a number of seats equal to its $u_{i}$ value (cf. Haman, 2003, pp. 132, 142).

${ }^{4}$ In my work (Haman, 2007), I suggested that this should be a value, for which the obtained distribution can be transformed into actual distribution as a result of the smallest possible number of shifts between states; this is a labour-intensive method and leads to determination of $r$ value in the form of an interval (albeit a very narrow one) and not a specific number (which results from the fact that the subject of matching is the distribution of seats, i.e. distribution already taking into consideration the rounding of the result to integers). Other solutions, leading to slightly different estimations of $r$ coefficient, are also possible.

5 Similarly, calculations for the other eleven allocations of seats in the EP for the years 1979-2013 (in 1979, EP was elected in general elections for the first time), lead to determination of the value between $r=0.697$ (in 1981) and $r=0.726$ (in 2009). Earlier allocations were slightly more degressive (in $1972 r=0.532$ ). 
6 In the case of proportional distribution, the "quota" corresponds to the population or the number of votes per one seat; in the case of degressively proportional distribution, the value of the "quota" would not have a clear interpretation.

7 The algorithms of the Webster-Sainte-Laguë method and Jefferson-d'Hondt method referring to the notion of quota and rounding, as well as the proof that they are the same as methods based on priority functions can be found, for example in (Young, 1994) or in (Haman, 2003).

8 This proof is a simple modification of the already mentioned proof of identity of the definition of Webster-Sainte-Laguë method based on quota and rounding, and on the priority function.

9 Own calculations; similarly, as in the case of the EP, calculations are made by curved linear regression of the distribution of seats in the Sejm according to the number of votes cast in favour of parties starting in the election using least squares regression method.

10 Own calculations, made similarly to the calculations concerning elections to the Polish parliament. The most recent (before 20 June 2016) elections in all EU Member States have been taken into consideration.

\section{R E F E R E N C E S}

Balinski, M. L., \& Young, H. P. (2001). Fair representation: meeting the ideal of one man, one vote. Brookings Institution Press.

Gallagher, M. (1991). Proportionality, disproportionality and electoral systems. Electoral Studies. Retrieved from http://www.sciencedirect.com/science/ article/pii/026137949190004C

Grimmet, G. (2011). The allocation between the EU member states of the seats in the European Parliament. Cambridge compromise. European Parliament Directorate General for Internal Policies, Policy Department C: Citizens' Rights and Constitutional Affairs.

Grimmett, G. (2011). Podział miejsc w Parlamencie Europejskim między państwa członkowskie. Kompromis z Cambridge. Parlament Europejski.

Haman, J. (2002). Podział mandatów pomiędzy okręgi wyborcze w świetle teorii sprawiedliwego podziału dóbr. Przeglad Sejmowy, 48(1), 9-34.

Haman, J. (2003). Demokracja, decyzje, wybory. Warszawa: Wydawnictwo Naukowe Scholar.

Haman, J. (2007). Degresywnie proporcjonalny podział mandatów w Parlamencie Europejskim. Decyzje, (8), 53-78.

Lamassoure, A., \& Severin, A. (2007). Report on composition of the European Parliament. Retrieved from http://www.europarl.europa.eu/sides/getDoc.do? pubRef $=-/ / \mathrm{EP} / / \mathrm{NONSgMl}+\mathrm{REPORT}+\mathrm{A} 6-2007-0351+0+\mathrm{DOC}+\mathrm{PDF}+\mathrm{v} 0$ $/ / \mathrm{EN}$

Ramírez-González, V. (2010). Degressive proportionality. Composition of the European Parliament. The parabolic method. ... Voting Power in the European Union .... Retrieved from http://ejournal.narotama.ac.id/files/Degressive 
The Concept of Degressive and Progressive Proportionality...

proportionality. Composition of the European Parliament. The parabolic method.pdf

Ramírez-González, V., Palomares, A., \& Márquez, M. (2006). Degressively proportional methods for the allotment of the European Parliament seats amongst the EU member states. Mathematics and Democracy. Retrieved from http://link.springer.com/chapter/10.1007/3-540-35605-3_15

Young, H. P. (1994). Equity: in theory and practice. Princeton University Press. Retrieved from http://www.econ.jhu.edu/People/Young/scans/Equity.pdf 